
8 Research Square
Preprints are preliminary reports that have not undergone peer review.
They should not be considered conclusive, used to inform clinical practice, or referenced by the media as validated information.

\title{
Factors Influencing Chiropractors Who Choose not to Join Professional Associations
}

\author{
Stanley I Innes ( $\nabla$ s.innes@murdoch.edu.au ) \\ Murdoch University, Australia https://orcid.org/0000-0001-7783-8328 \\ Vicki Cope \\ Kenneth J Young
}

\section{Research}

Keywords: Chiropractic, Professional associations

Posted Date: May 14th, 2020

DOI: https://doi.org/10.21203/rs.3.rs-27510/v1

License: (-) This work is licensed under a Creative Commons Attribution 4.0 International License. Read Full License 


\section{Abstract}

Background Professional associations are perceived to promote their professions and support their members. They can provide assistance with complaints, negotiate favourable professional indemnity insurance rates, provide access to research libraries and databases, and organise continuing professional development events. Despite these apparent advantages, about 1 in 3 Australian chiropractors choose not to belong to either of the two professional associations. Our study had three objectives: 1) to explore the views of non-member chiropractors about professional associations in general; and 2) seek to understand the motivations of nonmember Australian chiropractors about not joining a professional association; and 3) to discover their reasons that might lead them to join a professional association.

Methods This was a qualitative descriptive study utilising in-depth semi-structured interviews with open-ended questions for thematic analysis conducted from January to March 2020. It was estimated that between 6 -15 participants in total would be required to achieve saturation of data, that is, the point where no new themes were being articulated. Participants had to be registered chiropractors who had not been members of a professional association (PA) for the last five years. Recruitment was through a Facebook ad and snowball sampling. Interviews were transcribed and imported into NVivo qualitative analysis software, allowing identification of key concepts surrounding non-membership of chiropractic professional associations.

Results Five themes were identified from the data. They were: "Not worth the money", "Tarnished image of the profession", "Going it alone / what's in it for me", "Lack of visibility", and "Two warring factions". The most commonly voiced suggestions for improvement included providing continuing professional development/lectures, frequent email updates about events affecting practice/business, improve the image of the profession through the media, and act as a regulator to the profession.

Conclusions Non-members are looking for PAs to enhance the respectability of the profession in a manner that ultimately results in increased patient volume and the provision of readily accessible day-to-day resources and information. These results can inform the construction of a survey for the broader chiropractic non-membership community to confirm and expand upon these findings and improve PAs.

\section{Background}

Professional associations are perceived to play an important role in supporting their membership and improving the quality of the members working lives [1-3]. PAs have long seen their role as being a prominent voice for the profession to governments [4]. They promote their professions to the public, and support members when complaints are brought against them. They can often negotiate favourable professional indemnity insurance rates for members, provide access to research libraries and databases, and organise continuing professional development (CPD) events. The advantages seem so obvious that the authors were perplexed as to why in Australia, about 1 in 3 chiropractors choose not to belong to either of the two professional associations [5, 6]. This is not the same for other health professional organisations in Australia. For example, over $80 \%$ of physiotherapists and osteopaths are members of a professional association $[7,8]$. This raises the question of why this is it so?

Only two previous studies have examined determinants of professional chiropractic association membership. One in Wales [9] and the other in Australian chiropractic students [10]. These studies have identified both inhibitors and facilitators to joining a professional association. For chiropractic students, the influential factors on deciding whether or not to join a professional association (PA) related to developing the profession, developing personal practice, the reputation of the professional association and intra-professional communication [10]. Dispositional factors, such as personal values and opportunities for networking were also important. The sample of registered chiropractors from Wales also identified these factors as well as access to professional indemnity insurance, positive attitude to research and cost of membership [9].

\section{Rationale}

Given the lack of published Australian studies examining the influences on professional chiropractic association membership, and that one in three Australian chiropractors do not belong to a PA, it is important to undertake research that addresses this issue. To understand this, a qualitative approach focusing on learning the meanings behind an individual's choice to not belong to a professional chiropractic association was undertaken. Qualitative research has the ability to bring the honest narratives and shared 
experiences of people to the fore by providing detailed description of the topic under study, and through the interpretation and insight of the researcher can make sense and coherence of the data presented [11].

A qualitative methodology was chosen for several reasons. First it was anticipated there would be difficulty in accessing sufficient numbers of non-PA members for a quantitative study as they do not belong to common data base such as a PA. Also, there was a lack of any previous data to inform the construction of a quantitative approach such as a survey. Consequently, this methodology allowed for the easier collection of information to inform future quantitative studies.

\section{Aims}

This qualitative descriptive study had three objectives: 1) to explore the views of non-member chiropractors about professional associations in general; and 2) seek to understand the motivations of non-member Australian chiropractors about not joining a professional association; and 3) to discover their reasons that might lead them to join a professional association.

\section{Methods}

\section{Ethics}

Ethics approval was obtained from the Murdoch University Human Research Ethics Committee (2019/167) before recruitment and data collection. The study followed the COREQ guidelines for qualitative studies [12].

\section{Participant recruitment}

Inclusion criteria included full-time or part-time practicing chiropractors in Australia who had not been a member of any chiropractic professional association for 3 years or more.

Potential participants were recruited by placing a request in an Australian Chiropractic Facebook Group (881 members). In addition, snowball sampling was also used which involved participants and identifying additional participants from among their professional acquaintances. This sampling is a non-probability sampling technique used by researchers to identify potential participants for studies where respondents are hard to locate [13].

The first 8-12 chiropractors to respond to the invitation notice were emailed an information letter (Additional File 1) that detailed the purpose of the study, what participation entailed and their rights as participants. If they were agreeable to this, then they were invited to respond by signing the written consent and returning it to the lead investigator who enrolled them into the study. A suitable interview time for a Skype / Zoom / telephone interview was then arranged. Informed consent was obtained from each participant before commencing the interview.

\section{Participants}

A purposeful sample of chiropractors, that is those who were not members of a chiropractic association, were sourced with the number of participants for the study not determined. It was hoped that enough participants would be found, and that data saturation would be reached. Data saturation occurs when gathering fresh data no longer elicits new responses or information [14]. It was anticipated that between 6-15 participants in total may be required [14].

The interviews were conducted from January to April of 2020 and lasted an average of 30.2 minutes (25-42 minutes). There were nine participants ( 6 male, 3 female) with an average age of 38.8 years (24-57). Six described themselves as being in a relationship, 5 had at least one child, 2 practiced in a rural setting, with a mean 11.3 years of practice (3-34) and 9.9 years of non-membership (331). Other characteristics of the sample are not given to protect the anonymity of participants.

Interviews were conducted, transcribed, coded and analysed in-turn. The transcripts were reviewed by the lead researcher and then further reviewed and discussed with a qualitative research investigator (VC), as to whether thematic saturation had been reached. The researchers agreed that saturation was achieved after the ninth interview. Consequently, no further participants were sought.

\section{Data collection}

This was a qualitative descriptive study utilising in-depth semi-structured interviews with open-ended questions, at a time suitable to the participant via Skype / Zoom and telephone due to COVID-19 restrictions on face-to-face interviews. The interview questions were 
adapted from recent research that identified a number of barriers and facilitators to students considering chiropractic professional membership $[9,10]$. The full interview script (aide de memoir) is included in Additional file 1. In sum, chiropractors were asked for their views on chiropractic professional associations and asked to identify possible changes that the associations could make to increase their membership

The principal researcher $(S I)$ conducted the interviews $(n=9)$. The nine participants were provided with the information sheet prior to the interview and invited to reflect on factors that might influence chiropractors to decide not to join a professional association. Participants were also invited to make further comments as they felt appropriate to the topics under discussion during the interview. Participant responses were audio recorded on two digital devices and transcribed verbatim. The principal researcher also made notes to highlight important points and key aspects as they emerged at the time of the interview.

\section{Data Analysis}

All interviews were imported and analysed using the qualitative analysis NVivo 12 software in conjunction with manual coding and thematic analysis as outlined by Braun and Clarke [15], who noted that repeated readings results in familiarisation of the data and leads to identification of recurrent patterns and themes.

Trustworthiness of data and interpretation of the study involved four categories: credibility, transferability, dependability and confirmability [16]. To increase credibility, the transcriptions were returned to the interviewees for verification of accuracy. This ensured verification of data. The interviewer was familiar with the relevant literature and this helped ensure credible interpretation of the interactions with the participants, thus improving methodological rigour [17]. To attain dependability and confirmability of the data, the analysis process was reviewed by another qualitative expert (VC). The thematic analysis was supported by excerpts from the transcribed interviews and by reviewing field notes and reflective memos made during the interviews. Memos, field notes and reflections are a source of qualitative data as qualitative researchers aim to present a holistic account or the larger picture of the topic of interest [11]. Following these steps, the researchers were able to identify key concepts surrounding non-membership of chiropractic professional associations.

\section{Results}

\section{Findings / Recurring Themes.}

Five themes were identified from the data. They were: "Not worth the money", "Tarnished image of the profession", "Going it alone / what's in it for me", "Lack of visibility", and "Two warring factions".

In support of these themes, 'word trees' were developed from the verbatim quotes of the participants and are included to support the five themes. These are found in Appendix 1.

Theme 1: "Not worth the money / What's in it for me".

The respondents viewed chiropractic PAs as lacking in value for money and not worth the cost of annual membership. Some mentioned that PAs offered access to reduced professional indemnity and malpractice insurance rates as a temptation to join but as not being sufficient. Others spoke about financial hardship and choosing not to join as a way of making savings (Fig. 1 word tree).

R7: "My thoughts \& the ones from the people that l've spoken to from what l've understood, number one is cost, they really don't see any value in it".

\section{Theme 2: "Tarnished image of the profession"}

The most frequently recurring theme was a perception that the profession of chiropractic has a poor standing in the eyes of the public and other health professionals.

R1 "we worked so hard to be Chiropractors. And we study so much and know so much about the human body in this area or domain. And we are looked upon as worthless by the greater community. I don't like that. And it's not fair.. . it's the only profession that has this sort of thing happening to it that's going through a university-based model". 
Respondents thought the profession lacked homogeneity, unity, it was without recommended guidelines of care, and uniform treatments.

R8 "I'm not real comfortable with some of those other (chiropractic) techniques. And if they're big parts of gatherings I don't know whether I want to be part of that".

\section{Theme 3: "Going it alone"}

The chiropractic professions were not thought of as providing anything deemed to be essential for practice or of direct benefit to themselves. It was mentioned by three respondents that the decision not to re-join the PA was made after forgetting or overlooking the renewal date as becoming aware that there was no discernible difference whether they belonged or not. There appeared to be a high valuing of the individual and a low valuing of supporting the profession as a whole. Figure 2 is a 'word tree' developed from the verbatim quotes in support of this theme.

R1 "I kind of plod along without it being any direct impact on me .... I can kind of get by with not having to be a part of them".

Some spoke about being confident in their abilities and not needing the support offered by a PA, while others expressed discomfort with professional gatherings and assigned minimal value to group membership.

R4 "I haven't been part of that sort of group that get all funny about being professional and they go to all the seminars and all this sort of hype around the profession. I'm just not into it at all. Number one I don't have time to do it. And number two I just don't identify with that sort of professional thing".

\section{Theme 4: "Two warring factions"}

Within Australia there are two PA's. One is thought of as providing open membership that embraces all chiropractors' beliefs (from vitalism through to evidence-based practice) with the other describing itself as "evidence-based". The interviewees expressed views that recognised this spectrum within Australia PAs but also more broadly within the profession and they did not want to be seen as part of this disunity (Fig. 3 word tree).

R9 "The disagreement we have is obvious. . .some of us are on the philosophy or you know a lot of Chiropractors do things that are unfounded, let's say, or unproven, or unresearched or whatever term they use, but there are some of us who are evidence based. So, there's always this form of dissociation from part of the profession and in itself shows that the whole profession is weak".

\section{Theme 5: "Lack of visibility"}

Respondents expressed views indicating they perceived PAs as lacking a visible presence and this was perceived by some as being poor communication. Consequently, chiropractors were thought to not understand the full range of benefits that PAs provided. Respondents wanted this information to be easily accessible and were dissuaded from searching at the prospect of the level of difficulty involved (Fig. 4 word tree).

R4 "So maybe there needs to be a bit more awareness about what they're actually offering and why they're even there in the first place... . it feels like sometimes there's all this information out there that you have to sift through and find it in some random website somewhere".

This PAs were expected to be consistently working at being a high-profile presence in the day-to-day workplace with a range of relevant resources.

R6 "In general I guess making it more obvious, the benefits of joining. I mean I know that and you know that on their websites and they do have it .... to be honest you know, I kind of forget that they're there and unless I went and sought out that information"

\section{How to improve PAs.}

Finally, suggestions were sought from the nine respondents for actions PAs could undertake to increase the likelihood of nonmembers join. These are summarised and ranked from most frequently to least frequently occurring in Table 1. 
Table 1

Respondents suggestions for chiropractic PAs to increase the likelihood of non-members joining

Description of theme from most to least frequently suggested

Provide continuing education / lectures

Frequent email updates, especially practice / business / specific material E.g., such any regulatory changes or what is happening in the profession

Improve the image of profession through the media

Be seen to be regulating its membership

Increase patient numbers through effective use of the media

Create interest groups such as Sports Chiropractic / Paediatrics

Assist breaking down the barriers between professions

Assist with employment of new graduates

Cheaper membership

Guidelines for practice

Greater student support
Times mentioned

6

5

3

3

2

2

2

1

1

1

1

\section{Discussion}

\section{Overview}

Although there are few studies that have examined factors that positively impact on non-chiropractic health professionals' association membership, the most important predictor of membership seems to be an individual's perception of the value of association membership [18]. In particular, an individual's decision to join or remain in a professional association depends on whether they perceive that the benefits outweigh the costs [18]. We will consider each of the five themes that emerged from our research individually and propose solutions.

\section{Theme 1: Not worth the money}

The views of the respondents in this study were reflected in the findings of previous studies of the importance of benefit outweighing cost as an influencing factor for PA membership [18]. Perhaps this can be explained by Rational Choice theory which posits that individuals are purposive and intentional, seeking to achieve their given preferences [19]. To this end people tend to make choices to maximize their chances for achieving their preferences, generally driven by some tangible benefits [20]. Factors that were viewed as costs in this study and common to other health professionals were excessive membership fees [2], PA scandals [21] and disagreement with their positions and policies [2]. The chiropractors in this study did not share the concern of being so busy with work and family that they were time poor and consequently chose not to belong [22]. Shared factors that were viewed as benefits by the interviewed chiropractors in this study, Australian chiropractic students, and Welsh chiropractors were well priced membership while promoting the public and professional image of chiropractic, promoting research, providing workplace support and access to continuing professional development activities $[9,10]$. Continuing education and networking has also been found to be important to other health professionals $[18,23]$.

Another factor thought to be influential, but not reflected in non-chiropractic PA members responses in this study, is the presence of broader social forces [3]. Here people organize themselves in order to assert their personal interests, enhance their personal reputation, and gain access to desired goods. The classical example being a trade union. The non-influence could be explained, at least in part, by theme 4 of a preference of "going it alone".

Other social motives are thought to influential were the seeking to belong for principles of solidarity or ideological (political, ethical, or religious) convictions, as well as to be emotionally associated with the community. These were echoed in the recorded interviews as unfulfilled desires and deemed to be an unlikely occurrence in PAs. 
Several respondents suggested that PAs could help chiropractors improve their practices by making clinical guidelines available. This function already exists, as PAs provide seminars and continuing professional development to help members interpret and effectively use existing guidelines. Two possibilities exist. First the message of their availability is not reaching all members of the profession. Second, we have noticed that chiropractors seem to prefer 'feel good' seminars rather than research- and evidence-oriented ones. The latter seem to be perceived as 'boring'. This observation warrants further investigation.

\section{Theme 2: Tarnished image of the profession}

The experiences of interviewees provided insights into a chiropractic profession that they thought to be internally conflicted and viewed negatively by the wider community and other health professionals. This view appeared to cast a shadow over all the respondents' deliberations. The respondents' views on the respectability of chiropractic are not without reason. The occupation of chiropractic is not rated as prestigious by the public [24] nor by other healthcare professions [25]. This is not helped by an inadequately informed public about the nature of chiropractic care in Australia [26, 27]. Also, this is not unique to the profession of chiropractic, as studies with other health care professions have shown that scandals in PAs [21] and disagreement with PA positions and policies [2] resulted in lower levels of membership. Finally it should be borne in mind that a person's self-esteem is influenced by the degree to which other people value their role, and this may be a contributing factor as well [28].

There is a body of research exploring image repair that is relevant for Australian chiropractic PAs [29]. The main strategies are thought to be denial, evading responsibility, reducing offensiveness, mortification and corrective action [30]. When applied to chiropractic PAs, denial may involve convincing non-members that PAs did not create the current image for chiropractic, whereas evading responsibility could be to claim that the blame lay elsewhere e.g., a recalcitrant minority. Reducing offensiveness may be seeking to minimize the importance of the respectability issue and turn the tables by attacking those who raise accusations while at the same time promoting the PAs positive aspects. PAs could also communicate regret (mortification) and engage in corrective actions aimed at rectifying the damages. Finally, they could consider inoculating their members against likely future attacks against the profession by forewarning them of pending likely reputational attacks as well as providing members with creative counter arguments that weaken this threat. All of this presupposes that PAs have the resources (financial, expertise, person-power) to undertake these tasks and this may not be the case. It also assumes that image is the only barrier for non-PA members and this study suggests this is not the case.

Interestingly Australian chiropractic students, whose membership is free to PAs, did not see the image of the profession or PA as a barrier or facilitator to membership [10]. Perhaps the student population had not been exposed to the financial reality of day-to-day practice and overly rated the value of chiropractic as a profession in the communities' eyes?

\section{Theme 3: Going it alone / What's in it for me?}

The narratives of many participants seem to echo aspects of the choice to belong to large groups, however their focus was on their own individual needs rather than on those of the wider group [31]. This may not be specific to chiropractic as other health professionals are increasingly placing more importance on finding a good work-life balance and avoiding work related activities that infringe on family or enjoyable recreational activities [32]. It is possible that this may become the new norm as increasing numbers of younger health professionals are perceiving PAs as lacking in personal relevance [31].

Chiropractic practice in Australia can be insular, arising from a variety of historical, educational, and professional factors. Therefore, the finding of an individualistic mentality should not be surprising. Historically, chiropractic developed outside mainstream medicine, and medicine viewed chiropractic as a competitor, driving chiropractors to practice on their own [33]. Some chiropractors also had and have an alternative paradigm of health and disease, leading them to want or have little or no association with medicine [34]. Chiropractic education in Australia, although predominantly within the public university system, tends to stand alone within those universities, rather than be integrated with other health care disciplines. Nearly all chiropractors in Australia work in private practice [6]. Just over $75 \%$ work with another practitioner and this is overwhelmingly either another chiropractor or a masseur [6]. Only just over one half report of all chiropractors report receiving or making referrals to a medical practitioner and only $25 \%$ practice in more than one location [6]. Chiropractic is also largely excluded from the single-payer reimbursement system in Australia, and few chiropractors work in medical offices or hospitals [6].

Recent research has looked at the degree to which people in a society are integrated into groups and this theoretical framework is known as "Individualism and Collectivism" [35]. These two traits exist on a continuum, where those at the collectivistic end are more likely to show attentiveness to others and see themselves as exemplars of the larger group. At the individualistic end are people who

Page $7 / 16$ 
show self-directedness, autonomy, and independence and see themselves as makers of their own destiny. On the surface it appears that chiropractic PA non-members are more likely to possess individualistic traits and appears to require further investigations.

\section{Theme 4: Two warring factions}

The chiropractic profession is not homogeneous. Some practitioners see the practice of chiropractic as being an evidenced-based approach to musculoskeletal care (MSK) of the spine [36]. Others have adopted an alternative paradigm and believe that spinal manipulation has a role to play in disease and wellness more generally (Non-MSK) [37-39]. It is generally thought that the MSK and non-MSK factions exist as polar extremes with the majority falling somewhere in the middle [40]. The two factions strongly defend their own position and question the other's paradigm [41-43], to the extent that a recent discussion paper proposed that these differences as irreconcilable and the profession should consider divorcing along these lines [41]. The most recent example of this conflict being the claim from non-MSK practitioners that spinal manipulation can boost the human body's immune response and has a role to play in the management of the COVID-19 pandemic (Axen et al, in review). The MSK researchers and chiropractors (Axen et al, in review), as well as some chiropractic students (Plesner at al, in press CMT) responded by presenting the evidence to the contrary [44] and stated that any such claim was substandard, required regulatory intervention, and would likely result in reputation damage for the profession as a whole.

Several of the respondents in this study thought that PAs had a role to play by regulating substandard behaviour of its members. This is challenging when different chiropractors have fundamental differences in the definition of substandard behaviour. However, PAs are not able to sanction poor practice in any meaningful way. They are not empowered by statute to enforce laws or regulatory standards. They may not strike off ,suspend from practice, or fine members who transgress. Their only remedy is exclusion from the group. This form of punishment, equivalent to the ancient concept of banishment, holds little weight in chiropractic, as many practitioners do not highly value membership in the first place. However, the conflict between needing as many members as possible in order to fund various activities and taking an ethical stand to represent the highest standards of professionalism creates a conundrum for PAs. How can they best encourage professionalism in their members when many in the profession have no interest in their particular definition of professionalism, and will not join? How PAs respond to this issue will most likely be determined by their understanding of the reasons for their existence.

Finally, suggestions have been made that the way forward for the profession is through bringing these factions together and presenting a unified front by embracing all views to co-exist under the term chiropractor [45]. However, this 'big tent' approach, according to the respondents, may be another reason people do not to join, because they believe the association, in representing all permutations of chiropractic, does not adequately represent their particular views.

\section{Theme 5: Lack of visibility}

The PAs were perceived to be of inconsequential value to the workplace and as struggling to be visible. It is easy to speculate that the lack of visibility is related to a lack of desirability. A squabbling profession with a poor image, whose PAs are thought to be costly and largely irrelevant does not create a desirable image that is likely to 'catch the eye' of the siloed Australian chiropractic practitioner.

\section{Views on how PAs might improve themselves or membership}

In responding to questions concerning the ability of a PA to harness the many rather than the few, participants attitudes and motives reflected the emergent themes from the interviews as well as the findings of previous studies. The authors are aware that many of the suggested improvements are tasks already undertaken by both PAs in Australia. Both are involved with providing continuing education and frequently provide email updates. Further, they provide financial support to chiropractic students, run information programs for new graduates and have conducted seminars addressing the breaking down of barriers between the health professions. Obviously, there are other online options that may be more easily accessed, such as continuing education, that may detract from recognition of the Australian chiropractic PAs activity in these areas that might account, at least in part for this.

The insurance market also plays a part. Because chiropractors may obtain professional indemnity (malpractice) insurance independently, the group policies arranged by professional associations do not appear to be strong drivers for membership. It seems logical that groups can negotiate better rates than individuals, but they would need to be significant enough to encourage joining. Unfortunately for PAs the respondents in this study do not see this to be the case. 
Nonetheless, this raises questions as to the likelihood of non-members becoming members if PAs undertaking some or all of the tasks suggested that PAs are not currently doing. Some are clearly unobtainable because of the size of the financial cost for relatively small associations. For instance, a media campaign to improve the image of the profession and increase the volume of patients seeking chiropractic care would be prohibitively costly.

Several respondents expressed the desire for PAs to be involved in the creation and regulation of guidelines for clinical practice. As previously discussed, the profession is not uniform and has a variable understanding of chiropractic and its attendant scope of practice. Several researchers have expressed concerns about this diversity and called for a definition of chiropractic as an important and pressing need [46-48]. Without this the creation of guidelines for practice or regulation of the membership will be difficult if not impossible [49].

It seems apparent that there are no simple answers. It is easy to say that PAs should embrace public health and patient interest. After all, the leaders and rank-and-file members of PAs are health care professionals who enter into the fiduciary agreement with the public to put patient interests ahead of their own and those of their profession. But the simple reality is that PAs need money to survive, to lobby, to organise events, to maintain facilities and an online presence, so they need as many members as they can get. Ultimately, ensuring professional standards is not their job, but rather that of accrediting agencies and registration bodies. Accreditors must better ensure professional standards are taught in the schools and registration bodies must deal more comprehensively with legal and ethical transgressions. Only when there is unity regarding ethical behaviour in the profession can there be unity in the PAs.

\section{Strengths and limitations.}

This is the first study to explore chiropractors' views on why they chose not to belong to a representative PA. This study sampled the views of nine experienced Australian chiropractors with an average of nearly 10 years of non-membership in a PA. We are confident they have provided a rich insight into the issues surrounding non-membership in a chiropractic PA. However, as this was a qualitative study, our sample cannot be assumed to be representative of the views of all non-members of PA's nationally and internationally. The authors are confident they have addressed the issues surrounding qualitative research of reflexivity [50], credibility, transferability, dependability and confirmability [17].

\section{Future Research.}

A qualitative survey of a representative sample of non-PA members will ultimately confirm the degree to which the factors identified by the respondents in this study contribute to non-membership. On the surface it appears that chiropractic PA non-members are more likely to possess individualistic traits and any further studies should consider incorporating measures to this end.

This study when combined with the previous study of Australian chiropractic students' attitudes to PAs suggests that, for some, there is a change for the negative in their view of the profession. An exploration of the factors surrounding this change would necessarily be longitudinal in nature and may inform PAs of possible interventions to prevent or reduce the current high "drop out" rate.

\section{Conclusions}

This qualitative study set out to examine the views of chiropractors who do not belong to a PA to gain insights into why this may be the case and to garner suggestions for amending this situation. The issues of non-PA membership are intertwined with the image of the profession more broadly. Namely, there is a perception of an unenticing profession that is internally conflicted and poorly rated by both the public and other health care professionals. PAs themselves are viewed as not providing enough support or resources on a day-to-day basis to justify the cost or the effort to search them out. There is the possibility that personal traits and societal pressures may act as modifiers or mediators. Non-members are looking for PAs to enhance the respectability of the profession in a manner that ultimately results in increased patient volume and the provision of readily accessible day-to-day resources and information. Many of these may be non-modifiable and as such present as enormous challenges for growing Australian PA membership. These results can inform the construction of a survey for the broader chiropractic non-membership community to confirm and expand upon these findings as well as seek solutions. 


\section{List Of Abbreviations}

CPD

Continuing Professional Development

PA

Professional Association

\section{Declarations}

\section{Ethics Approval and Consent to Participate}

Ethics approval was granted from Murdoch University Human Research and Ethics Committee (Project No 2019/167).

\section{Consent for publication}

Not applicable

\section{Availability of data and materials}

Not applicable

\section{Competing interests}

Stanley Innes (SI) is a Board Member of Chiropractic Australia.

\section{Funding}

Chiropractic Australia provided partial funding for this project.

\section{Authors' contributions}

SI, and NS were responsible for conceptualising the study. SI, NS and VC reviewed the transcripts for thematic development. SI and KY developed the initial draft. All contributed to the final version. All authors read and approved the final manuscript.

\section{Acknowledgements}

Dr Norman Stomski was part of the conceptualising of this study and the reviews of transcripts for thematic identification. His unexpected death during this study was a loss to the research community. We wish to acknowledge his contribution to this study and the richness he added to our lives.

\section{References}

1. Lowe G, Jennings T: Nurse Practitioner Professional Nursing Organisation Engagement. The Journal for Nurse Practitioners 2017, 13(9):642.

2. Farina CA, Wilson W, FitzSimmons K: Exploring Strategies to Increase and Sustain Membership in the American Association of Nurse Anesthetists. AANA journal 2016, 84(6):396-403.

3. Weber M: The theory of social and economic organization: Simon and Schuster; 2009.

4. Merton RK: The functions of the professional association. The American journal of nursing 1958:50-54.

5. Chiropractic Board of Australia [https://www.chiropracticboard.gov.au/] 
6. Adams J, Lauche R, Peng W, Steel A, Moore C, Amorin-Woods LG, Sibbritt D: A workforce survey of Australian chiropractic: the profile and practice features of a nationally representative sample of 2,005 chiropractors. BMC complementary and alternative medicine 2017, 17(1):14.

7. APA Strategic Plan for $\mathbf{2 0 1 8}$ and beyond [https://australian.physio/aboutus/annual-reports]

8. Orrock P: Profile of members of the Australian Osteopathic Association: Part 1-The practitioners. Int J Osteopath Med 2009, 12(1):14-24.

9. Wotherspoon SE, McCarthy PW: The factors and motivations behind United Kingdom chiropractic professional association membership: a survey of the Welsh Institute of Chiropractic Alumni. Chiropr Man Therap 2016, 24(1):35.

10. Innes SI, Stomski N, Theroux J: Chiropractic students' perceptions of barriers and facilitators to joining a professional association". Chiropr Man Therap 2019, 27:67.

11. Creswell JW, Creswell JD: Research design: Qualitative, quantitative, and mixed methods approaches: Sage publications; 2017.

12. Tong A, Sainsbury P, Craig J: Consolidated criteria for reporting qualitative research (COREQ): a 32-item checklist for interviews and focus groups. International journal for quality in health care 2007, 19(6):349-357.

13. Sadler GR, Lee HC, Lim RSH, Fullerton J: Recruitment of hard-to-reach population subgroups via adaptations of the snowball sampling strategy. Nursing \& health sciences 2010, 12(3):369-374.

14. Creswell JWP, CN: Qualitative Inquiry and Research Design: Choosing Among Five Approaches, 4 edn. Los Angeles: Sage; 2018.

15. Braun V, Clarke V: Using thematic analysis in psychology. Qualitative research in psychology 2006, 3(2):77-101.

16. Lincoln YS, Guba EG: Naturalistic inquiry, vol. 75: Sage; 1985.

17. Whittemore R, Chase SK, Mandle CL: Validity in qualitative research. Qualitative health research 2001, 11(4):522-537.

18. White MJ, Olson RS: Factors affecting membership in specialty nursing organizations. Rehabil Nurs 2004, 29(4):131-137.

19. Friedman D, Hechter M: The contribution of rational choice theory to macrosociological research. Sociological theory 1988:201218.

20. Opp K-D: Contending conceptions of the theory of rational action. Journal of theoretical politics 1999, 11(2):171-202.

21. Boddiger D: AMA hopes streamlined agenda will boost membership. The Lancet 2005, 366(9490):971-972.

22. Deleskey K: Factors affecting nurses' decisions to join and maintain membership in professional associations. Journal of perianesthesia nursing : official journal of the American Society of PeriAnesthesia Nurses 2003, 18(1):8-17.

23. Fusco NM, Prescott GM, Prescott Jr WA: Motivations for pharmacy students to join professional organizations. Currents in Pharmacy Teaching and Learning 2015, 7(1):117-120.

24. Wardwell WI: A marginal professional role: the chiropractor. Social forces 1952:339-348.

25. Nurses Top List of Most Honest and Ethical Professions. Gallup News Service [https://news.gallup.com/poll/25888/nurses-toplist-most-honest-ethical-professions.aspx]

26. Wilson K, Swincer K, Vemulpad S: Public perception of chiropractic: a survey. Chiropractic Journal of Australia 2007, $37(4): 135$.

27. Brown BT, Bonello R, Fernandez-Caamano R, Graham PL, Eaton S, Green H: Chiropractic in Australia: a survey of the general public. Chiropractic journal of Australia 2013, 43(3):85-92.

28. Reitz AK, Motti-Stefanidi F, Asendorpf JB: Me, us, and them: Testing sociometer theory in a socially diverse real-life context. $J$ Pers Soc Psychol 2016, 110(6):908-920.

29. Benoit WL: Accounts, excuses, and apologies: A theory of image restoration strategies: Marcombo; 1995.

30. Compton J: Image prepare: Image repair, inoculation theory, and anticipated attacks on credibility. International Journal of the Image 2017, 8(1).

31. Collier R: American Medical Association membership woes continue. CMAJ 2011, 183(11):E713-714.

32. Pryor KH: Membership Trends in the Health Physics Society: How Did We Get Here and Where Are We Going? Health physics 2017, 112(2):131-138.

33. Moore JS: Chiropractic in America: the history of a medical alternative: Johns Hopkins University Press; 1993.

34. McGregor M, Puhl AA, Reinhart C, Injeyan HS, Soave D: Differentiating intraprofessional attitudes toward paradigms in health care delivery among chiropractic factions: results from a randomly sampled survey. BMC complementary and alternative medicine 2014, 14:51. 
35. Iacoviello V, Lorenzi-Cioldi F: Collectivism and Individualism in Status Hierarchies: Socialization and Social Identity Explanations. International Review of Social Psychology 2019, 32(1).

36. Schneider M, Murphy D, Hartvigsen J: Spine Care as a Framework for the Chiropractic Identity. Journal of chiropractic humanities 2016, 23(1):14-21.

37. Vernon H: Historical overview and update on subluxation theories. Journal of chiropractic humanities 2010, 17(1):22-32.

38. Good CJ: The great subluxation debate: a centrist's perspective. Journal of chiropractic humanities 2010, 17(1):33-39.

39. Chiropractic: The effects of the adjustment [https://www.heidihaavik.com/collections/brochures/products/how-chiropracticworks-brochure?variant $=525654297]$

40. Glucina T. KC, Farvid P., Holt K: Moving towards a contemporary chiropractic professional identity. Complementary therapies in clinical practice 2020, 39.

41. Leboeuf-Yde C, Innes SI, Young KJ, Kawchuk GN, Hartvigsen J: Chiropractic, one big unhappy family: better together or apart? Chiropractic \& Manual Therapies 2019, 27(1):4.

42. Reggars JW: Chiropractic at the crossroads or are we just going around in circles? Chiropr Man Therap 2011, 19:11.

43. Simpson JK: The five eras of chiropractic \& the future of chiropractic as seen through the eyes of a participant observer. Chiropractic \& manual therapies 2012, 20(1):1.

44. The Effect of Spinal Adjustment / Manipulation on Immunity and the Immune System: A Rapid Review of the Relevant Literature [https://www.wfc.org/website/images/wfc/Latest_News_and_Features/Spinal_Manipulation_Immunity_Review_2020_03_19.pdf]

45. McCoy M: Editors Perspective; Unity Through Tolerance. Journal of Vertebral Subluxation Research 2007, May, 10:1-4.

46. Hartvigsen J, French SD: So, what is chiropractic? Summary and reflections on a series of papers in Chiropractic and Manual Therapies. Chiropr Man Therap 2020, 28(1):4.

47. Innes SI, Cope V, Leboeuf-Yde C, Walker BF: A perspective on Chiropractic Councils on Education accreditation standards and processes from the inside: a narrative description of expert opinion: Part 1: Themes. Chiropr Man Therap 2019, $27: 57$.

48. Innes SI, Leboeuf-Yde C, Walker BF: Similarities and differences of a selection of key accreditation standards between chiropractic councils on education: a systematic review. Chiropr Man Therap 2016, 24:46.

49. Rapport F, Clay-Williams R, Churruca K, Shih P, Hogden A, Braithwaite J: The struggle of translating science into action: Foundational concepts of implementation science. J Eval Clin Pract 2018, 24(1):117-126.

50. Malterud K: Qualitative research: standards, challenges, and guidelines. The lancet 2001, 358(9280):483-488.

\section{Figures}




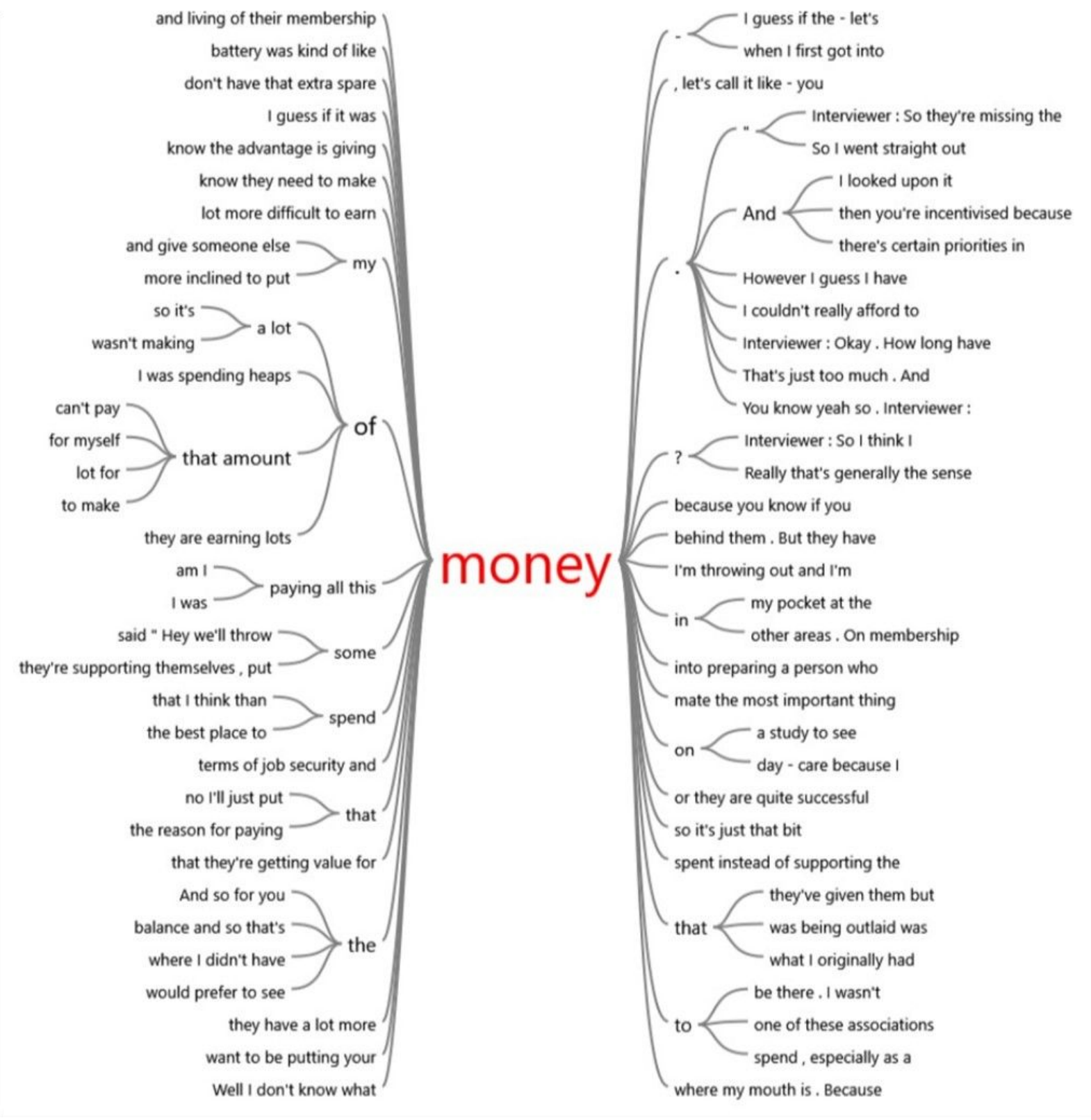

\section{Figure 1}

Theme "Not worth the money" / "Cost". Nvivo generate word tree. 


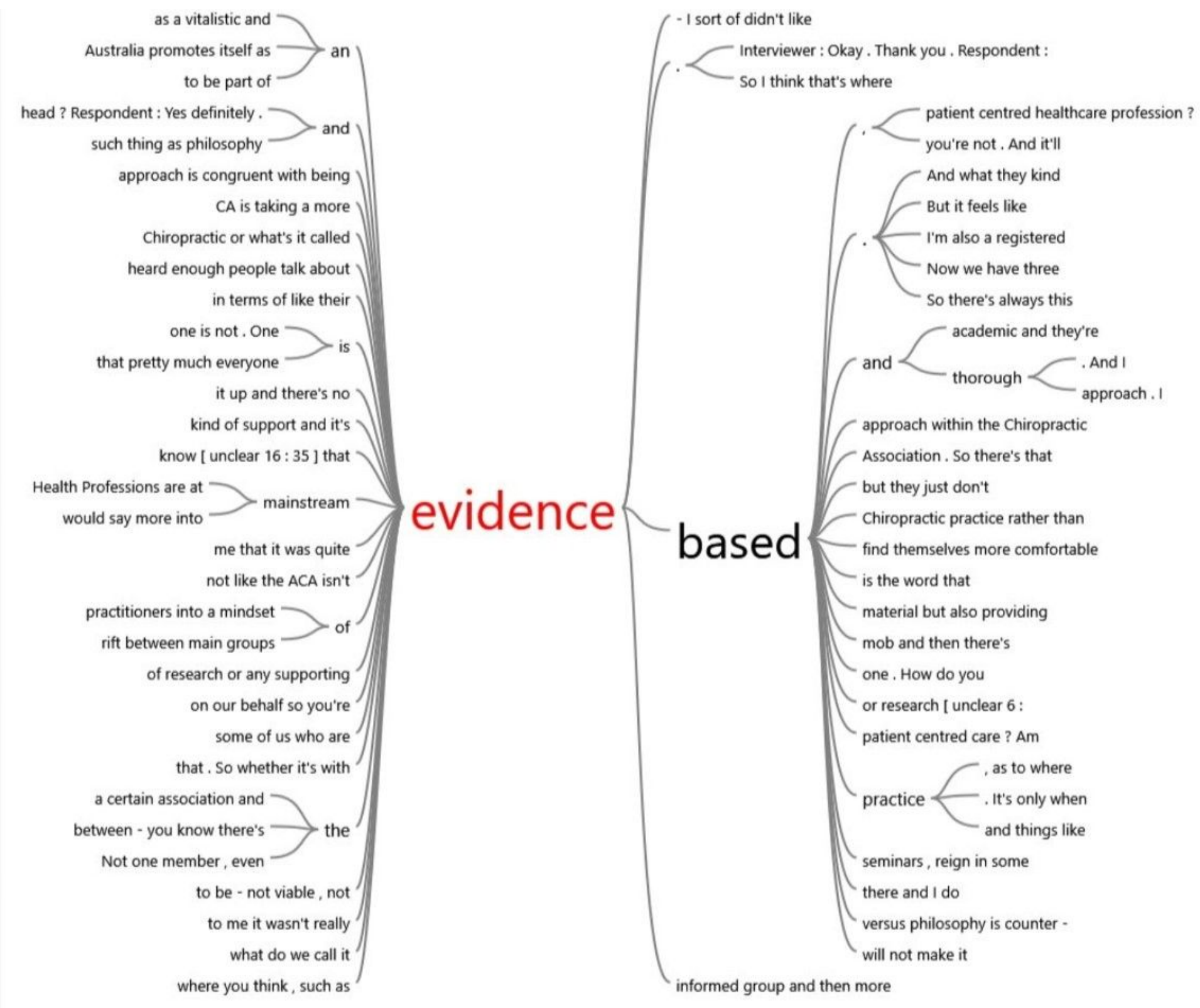

\section{Figure 2}

Theme "Waring factions'. Nvivo generated word tree 


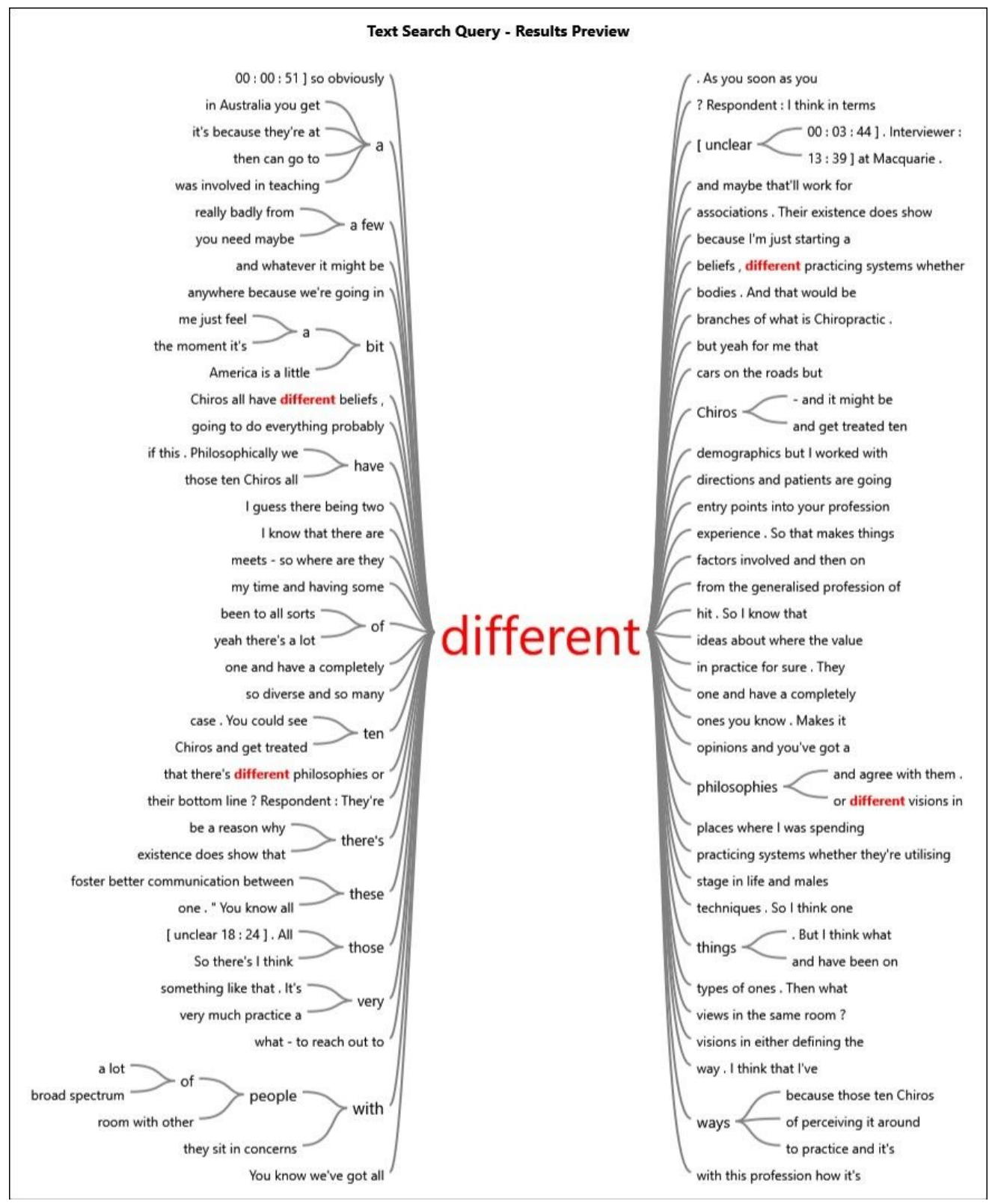

\section{Figure 3}

Theme "Going it alone / Different" Nvivo generated word tree 


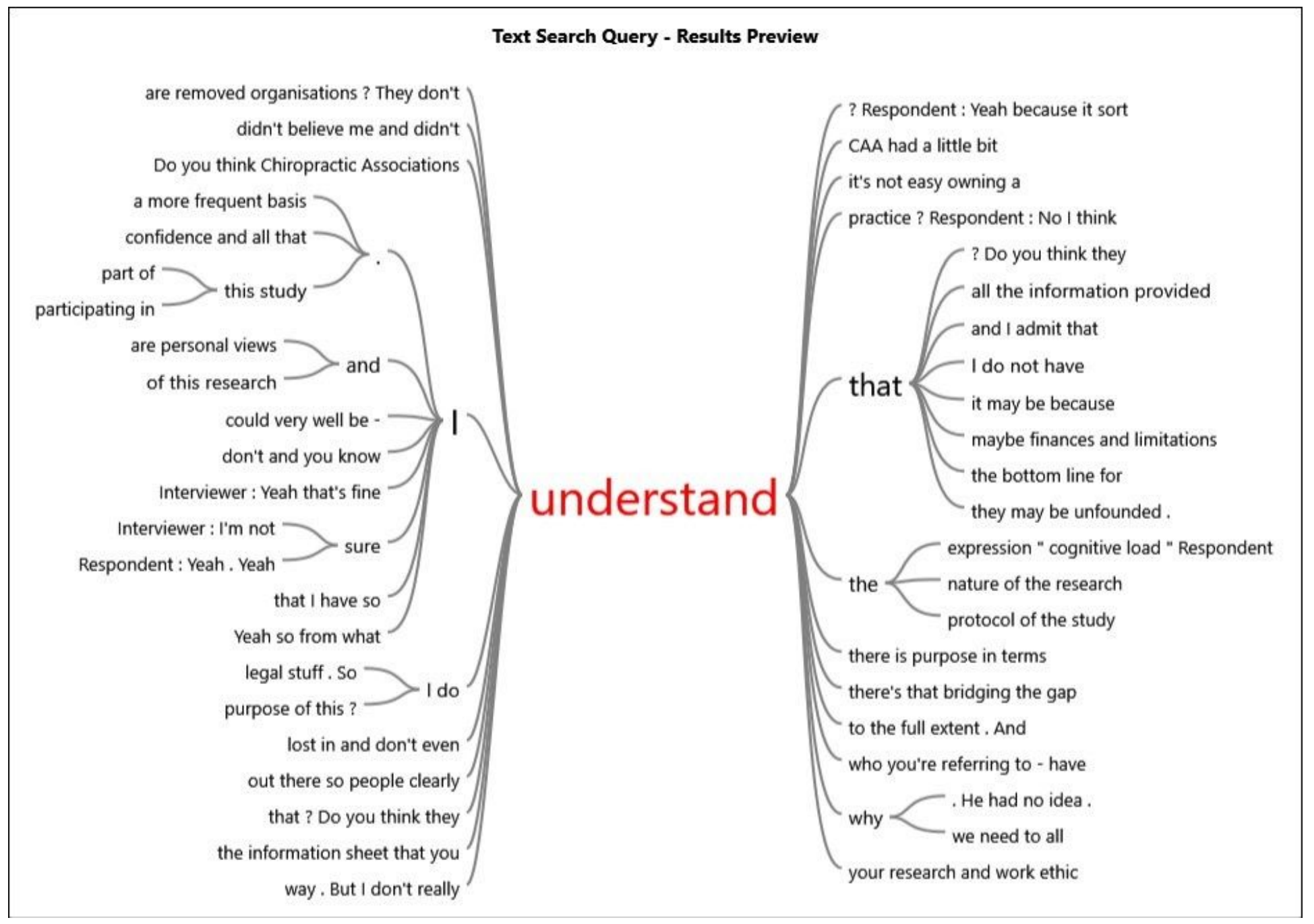

Figure 4

Theme "communication issues" Nvivo generate word tree

\section{Supplementary Files}

This is a list of supplementary files associated with this preprint. Click to download.

- Appendix1CMTSubmitNonQual2020.docx 